\title{
Một số vấn đề lý luận trong nghiên cứu thúc đẩy hình thành doanh nghiệp công nghệ thông qua vườn ươm doanh nghiệp công nghệ
}

\author{
Phạm Đại Dương ${ }^{1}$, Đào Thanh Trường ${ }^{2, *}$ \\ ${ }^{1}$ Bộ Khoa học và Công nghệ, 113 Trần Duy Hung, Hà Nội, Việt Nam \\ ${ }^{2}$ Trưòng Đại học Khoa học Xã hội và Nhân văn, ĐHQGHN, \\ 336 Nguyến Trãi, Hà Nội, Việt Nam \\ Nhận ngày 9 tháng 7 năm 2017 \\ Chỉnh sửa ngày 20 tháng 9 năm 2017; Chấp nhận đăng ngày 10 tháng 10 năm 2017
}

\begin{abstract}
Tóm tắt: Khái niệm vườn ươm doanh nghiệp xuất hiện ở Việt Nam gần chục năm nay, tuy nhiên, đối với phần đông doanh nghiệp và người dân, thuật ngữ này vẫn còn khá mới mẻ. Chính vì lý do đó, những tác giả nghiên cứu về ươm tạo doanh nghiệp công nghiệp không nhiều và mới chỉ dừng lại ở việc nhận diện những khó khăn ở một trung tâm ươm tạo, đưa ra những đề án xây dựng vườn ươm cụ thể, tuy nhiên, cơ sở ươm tạo doanh nghiệp công nghệ ở Việt Nam chưa được nhìn nhận một cách tổng thể và chưa được đánh giá một cách toàn diện. Vườn ươm doanh nghiệp công nghệ (technology business incubator) là một dạng của vườn ươm doanh nghiệp tập trung vào ươm tạo các doanh nghiệp dựa trên công nghệ (technology based enterprise). Vườn ươm doanh nghiệp công nghệ có thể được xem như một môi trường chuyển giao kết quả nghiên cứu từ khu vực nghiên cứu hàn lâm đến thị trường, khuyến khích hoạt động đổi mới, là nơi nuôi dưỡng và hình thành doanh nghiệp công nghệ, là công cụ chính sách để hỗ trợ phát triển và khởi tạo DNNVV. Ngoài ra, tác giả bàn sâu thêm về vai trò của vườn ươm doanh nghiệp công nghệ cũng như ba giai đoạn của hoạt động ươm tạo bao gồm: tiền ươm tạo, ươm tạo và hậu ươm tạo với những quy trình và đặc điểm riêng.
\end{abstract}

Tù khóa: Doanh nghiệp công nghệ, TBI, vườn ươm doanh nghiệp công nghệ, vườn ươm doanh nghiệp.

\section{Mở đầu}

Trong hệ thống đổi mới sáng tạo quốc gia, doanh nghiệp, đặc biệt là các doanh nghiệp nhỏ và vừa đóng vai trò tối quan trọng trong việc kết nối các thành tố như chính phủ đến các tổ chức R\&D (Trường đại học; Viện nghiên cứu) và thị trường. Theo nghiên cứu chung, các

\footnotetext{
*Tác giả liên hệ. ĐT.: 84-913016429.

Email: truongkhql@gmail.com

https://doi.org/10.25073/2588-1116/vnupam.4125
}

doanh nghiệp nhỏ và vừa, đặc biệt là các doanh nghiệp siêu nhỏ ở các nước đang phát triển thiếu các nguồn lực cần thiết để mở rộng quy mô và phát triển doanh nghiệp một cách hiệu quả nhất. Các doanh nghiệp này chưa tìm kiếm được cơ hội lớn để đổi mới, tạo việc làm và tạo giá trị. Nhiều nghiên cứu đã chỉ ra rằng các vườn ươm doanh nghiệp đặc biệt là các vườn ươm doanh nghiệp công nghệ trong các trường đại học, khu công nghệ cao hay tự hình thành là một công cụ hiệu quả để hỗ trợ sự đổi mới trong nước và tạo ra những doanh nghiệp công 
nghệ mới, đồng thời giảm tỷ lệ thất bại của các doanh nghiệp công nghệ nhỏ và vừa một cách đáng kể, xây dựng được mối liên kết mạnh giữa cung - cầu các sản phẩm khoa học và công nghệ (KH\&CN).

Vườn ươm doanh nghiệp công nghệ là mô hình tổ chức thực hiện chức năng hỗ trợ các nhóm người hoạt động trong lĩnh vực khoa học - công nghệ, các doanh nghiệp, hoặc các doanh nhân được tổ chức trong giai đoạn khởi nghiệp để hoàn thiện các quy trình tạo ra các công nghệ mới, các sản phẩm mới được xuất hiện từ các ý tưởng hoặc các kết quả nghiên cứu triển khai công nghệ. Các vườn ươm này là chiếc nôi nuôi dưỡng công nghệ mới, sản phẩm mới và tạo các điều kiện thuận lợi cho việc hình thành các doanh nghiệp mới để sản xuất hoặc kinh doanh các sản phẩm được nuôi dưỡng tại vườn ươm; hoặc hỗ trợ cho việc thúc đẩy các doanh nghiệp thương mại hoá các sản phẩm khoa học - công nghệ mới. Và đặc biệt, các vườn ươm có vai trò lớn trong việc thương mại hoá kết quả nghiên cứu công nghệ, thúc đẩy tạo điều kiện cho việc hình thành và khởi nghiệp các doanh nghiệp công nghệ.

Việc ứng dụng khoa học và công nghệ là thành tố chính để phát triển công nghiệp, kinh tế và xã hội của một quốc gia. Với sự gia tăng toàn cầu hóa và việc nhận thức được tầm quan trọng của "xã hội tri thức", mối liên kết giữa sản xuất tri thức trong các trường đại học, viện nghiên cứu và sử dụng tri thức trong ngành công nghiệp, khu vực tư nhân và khu vực công là yếu tố thiết yếu cho việc đổi mới và thương mại hóa kết quả nghiên cứu và triển khai (R\&D).

Hiện nay trên thế giới có rất nhiều mô hình cơ sở ươm tạo doanh nghiệp công nghệ như: mô hình đơn sở hữu, đa sở hữu; công lập, tư nhân; phát triển cơ sở ươm tạo thông qua hồ trợ của mạng lưới các doanh nghiệp; hợp tác quốc tế; mô hình cơ sở ươm tạo tại trường đại học,,.. Sự phát triển và thành công của mô hình cơ sở ươm tạo doanh nghiệp công nghệ tại các nước trên thế giới như Trung Quốc, Thụy Điển, Mỹ,... và ngay tại quốc gia trong khu vực như Trung
Quốc, Hàn Quốc, Đài Loan, Singapore,... đã chứng minh vai trò tích cực của mô hình cơ sở ươm tạo. Xét về vai trò và ý nghĩa của cơ sở ươm tạo doanh nghiệp công nghệ:

Thứ nhất, cơ sở ươm tạo doanh nghiệp tạo điều kiện, là chất xúc tác giúp các doanh nghiệp khởi sự thành công, phát triển tinh thần kinh thương.

Thứ hai, đây được coi là công cụ thúc đẩy sáng tạo, đồi mới, chuyển giao công nghệ và thương mại hoá thành công các ý tưởng công nghệ nhờ gắn kết chắt chẽ hơn mối quan hệ trường đại học - viện nghiên cứu - doanh nghiệp.

Thứ ba, cơ sở ươm tạo có tác động tích cực tới mối quan hệ Doanh nghiệp- Chính phủ, là nơi kiểm nghiệm sự phù hợp, hiệu quả của các chính sách của chính phủ.

Thứ tư, cung cấp quỹ hạt giống (seed funding) cho các doanh nghiệp khởi nghiệp hoặc giúp đõ̃ các doanh nghiệp tìm kiếm, gia tăng nguồn vốn hạt giống.

Thứ năm, đóng vai trò kết nối các doanh nghiệp khởi nghiệp với mạng lưới nguồn lực để gia tăng cơ hội sống sót và tăng trưởng.

Chính vì những lợi ích trên mà cơ sở ươm tạo doanh nghiệp công nghệ đã trở thành một bước đi thiết yếu cho sự phát triển và đổi mới hoạt động khoa học và công nghệ của các quốc gia.

Giai đoạn phát triển kinh tế của Việt Nam khoảng 10 năm qua đã chứng kiến sự hình thành và phát triển rất năng động của phong trào khởi nghiệp. Với việc thừa nhận vai trò to lớn của doanh nghiệp khởi nghiệp đối với sự phát triển kinh tế, tạo công ăn việc làm và đảm bảo an sinh xã hội. Hơn nữa, việc phát triển hệ thống doanh nghiệp $\mathrm{KH} \& \mathrm{CN}$ được khẳng định là một trong những mục tiêu quan trọng trong chiến lược phát triển KH\&CN giai đoạn 2011 2020 của Đảng và Nhà nước. Theo đó, các cơ sở ươm tạo nhận rõ được trách nhiệm và mục tiêu của mình trong tương lai trong việc hỗ trợ để thúc đẩy hoạt động khởi nghiệp. 


\section{Một số khái niệm cần được thống nhất hóa trong nghiên cứu}

2.1. Vuờn ươm doanh nghiệp, vườn ươm doanh nghiệp công nghệ

Khái niệm vườn ươm doanh nghiệp (business incubator) xuất xứ từ Mỹ vào đầu những năm 50 (do thị trưởng Watertown, New York - Frank Mancuso - sử dụng khu nhà xưởng/công trình trước đây để ươm trứng gà dùng làm nơi cung cấp diện tích làm việc cho các doanh nghiệp khởi sự). Thuật ngũ "incubator" có thể được dịch theo nhiều cách khác nhau: vườn ươm, lồng ươm, lò ủ, nơi ấp ủ, ... Theo từ điển Oxford, vườn ươm là dụng cụ cung cấp nhiệt ấp trứng, nuôi trẻ em đẻ non hoặc nuôi vi khuẩn.

Ươm tạo doanh nghiệp chính thức bắt đầu ở Mỹ trong những năm 1960, và sau đó phát triển ở Anh và châu Âu thông qua các hình thức khác nhau có liên quan (ví dụ. các trung tâm đổi mới, công viên khoa học). Nó được công nhận là một cách đáp ứng một loạt các nhu cầu chính sách kinh tế và kinh tế xã hội trong đó có thể bao gồm:

+ Việc làm

+ Hỗ trợ cho các doanh nghiệp nhỏ với tiềm năng tăng trưởng cao

+ Chuyển giao công nghệ

+ Thúc đẩy đổi mới

+ Tăng cường liên kết giữa các trường đại học, viện nghiên cứu và cộng đồng doanh nghiệp phát triển cụm công nghiệp

+ Đánh giá hồ sơ rủi ro của công ty

Theo Hiệp hội Quốc gia các Vườn ươm doanh nghiệp (The National Business Incubation Association - NBIA), vườn ươm doanh nghiệp là một môi trường và chương trình với một số đặc tính quan trọng như cung cấp một danh sách đầy đủ các dịch vụ hỗ trợ doanh nghiệp theo yêu cầu riêng của các doanh nghiệp khách hàng; có một giám đốc vườn ươm tại chỗ điều phối các nhân viên, các chuyên gia bên ngoài và các tổ chức để cung cấp các dịch vụ hỗ trợ doanh nghiệp; giúp các doanh nghiệp trưởng thành một khi các doanh nghiệp đạt được các mục tiêu của chương trình (mặc dù không vượt ra ngoài các phương tiện và trang thiết bị của chương trình) [1].

Theo Tổ chức Phát triển Công nghiệp của Liên hiệp quốc (UNIDO) thì "TBI là một tổ chức tiến hành một cách hệ thống quá trình tạo dưng các doanh nghiệp móit, cung cấp cho các doanh nghiệp này một hệ thống toàn diện và thich hơp các dịch vu để hoạt động thành công” [1]. Các TBI không nhất thiết phải có tất cả các thiết bị và dịch vụ, mà thông qua việc kết hợp các nguồn lực của các nhà cung cấp dịch vụ bên ngoài để đảm bảo cho các doanh nghiệp trong TBI có điều kiện hoạt động.

Tổ chức Vườn ươm doanh nghiệp của Anh (United Kingdom Business Incubation - UKBI) thì định nghĩa "uoom tạo doanh nghiệp là biểu hiện vật lý của quá trình nhằm khuyến khich con ngườ bắt đầu hình thành và phát triển một doanh nghiẹpp, cung cấp cho doanh nghiẹp đó nhũng nguồn lực để đạt được thành công và tạo mọt môi trường cho doanh nghiệp có thể phát triển"'[2].

Theo Hướng dẫn của Hiệp hội Trung tâm đổi mới và Công viên khoa học (Science Park and Innovation Center Association's Directory SPICA) cho rằng, "vườn ươm doanh nghiệp là một thực thể được thiết kế để phát triển kinh tế xã họi huớng đến nhũng doanh nghiệp khởi nghiệp tiềm năng, giúp chúng thiết lập, quản lý sự phát triển và thành công thông qua một chưong trình hỗ trợ toàn diện. Muc đich chinh là tạo ra nhũng doanh nghiệp thành công có khả năng đứng vĩng và độc lập về tài chính. Nhũng doanh nghiệp tốt nghiệp này sẽ tạo ra việc làm, đem lại sức bật cho công đồng, thuơng mại hóa công nghệ mói, tăng cường kinh tế cho địa phưong và quốc gia.

Những công việc chính của vườn ươm là:

Quản lý nhằm phát triển và sắp xếp kinh doanh, tiếp thị và quản lý các nguồn lực và các mối quan hệ phù hợp với nhu cầu của khách hàng doanh nghiệp.

Chia sẻ các dịch vu văn phòng, đào tạo, hỗ trọ̣ công nghệ và trang thiết bị. 
Lựa chọn khách hàng và quá trình tăng tốc mà theo đó các doanh nghiẹp trở nên độc lập hon và tiến tới tốt nghiệp.

Hỗ trợ để có được nguồn tài chính cần thiết cho sụ tăng trưởng kinh doanh.

Cung cấp không gian cho thuê thich hợp và hơp đồng thue linh hoạt trong vuờn ưom " [3].

Các định nghĩa nêu trên là tương tự như định nghĩa áp dụng ở nhiều nước khác. Theo Trung tâm Chuyển giao công nghệ (Mỹ) thì vườn ươm công nghệ "là một tổ chưc được thiết kế để thúc đẩy các doanh nghiệp phát triển và thành công bằng việc cung cấp những nguồn lục và dịch vu hồ trợ bao gồm vốn, huấn luyện, không gian, nhũng dịch vu thông thuờng và kết nối mang luói. Mục đích chính của vườn vơm doanh nghiệp là tạo ra các doanh nghiệp thành công mà khi rời khỏi vườn uoom có khả năng đứng vũung được về tài chính và đứng một cách độc lập để thuơng mại hóa các công nghệ mới và tạo ra việc làm" [4].

Tại Việt Nam thuật ngữ "ươm tạo công nghệ" và "Ươm tạo doanh nghiệp công nghệ" đã xuất hiện trong các văn bản quy phạm pháp luật bắt đầu từ năm 2006 theo đó:

Khoản 19 Điều 3 của Luật Chuyển giao công nghệ 2006 quy định: "Ươm tạo công nghệ (technology incubation): là hoạt động hỗ trợ nhằm tạo ra và hoàn thiện công nghệ có triển vọng ứng dụng thực tiễn và thương mại hóa từ ý tưởng công nghệ hoặc kết quả nghiên cứu khoa học và phát triển công nghệ" [5].
Khoản 20 Điều 3 Luật Chuyển giao công nghệ 2006 về ươm tạo doanh nghiệp công nghệ quy định: "Uơm tạo doanh nghiẹp công nghệ là hoạt động hỗ trọ" tổ chức, cá nhân hoàn thiện công nghệ, huy động vốn đầu tu, tổ chức sản xuất, kinh doanh, tiếp thị, thực hiện thủ tục pháp lý và các dịch vu cần thiết khác để thành lạp doanh nghiệp sư dụng công nghệ mói được tao ra" [5].

Theo điều 3 quyết định của Thủ tướng Chính Phủ về việc thí điểm một số cơ chế, chính sách đặc thù phát triển vườn ươm công nghệ công nghiệp Việt nam - Hàn Quốc tại thành phố Cần Thơ đã giải thích: "Vườn ươm là co sở nghiên cứu khoa hoc, uoom tạo và phát triển công nghệ trong các lĩnh vưc công nghiệp chế biến nông sản; công nghiệp chế biến thưy sản; công nghiệp cơ khi chế tạo phuc vu chế biến nông, thủy sản; hỗ trợ các doanh nghiẹp khởi nghiẹpp; hố trọ đào tạo nguồn nhân lực. Vườn uoom bao gồm khu vuoòn ươm với diện tích khoảng 200ha được Ủy ban nhân dân thành phố Cần Tho giao quản lý và tru sở Vuoòn uoom đặt tại Khu công nghiệp Trà Nóc 2, thành phố Cần Tho: Vườn uoom được xây dụng bằng nguồn vốn viện trọ̆ phát triển không hoàn lại của Chính phủ Hàn Quốc và vốn đổi ứng của Chính phủ Việt Nam" [6].

Từ các định nghĩa trên, ta có thể thấy vườn ươm doanh nghiệp được chia thành thành các loại như sau:

\begin{tabular}{|c|c|}
\hline $\begin{array}{l}\text { Vườn ươm doanh nghiệp } \\
\text { (VUDN) (business incubator) }\end{array}$ & $\begin{array}{l}\text { Nơi cung cấp cơ sở vật chất, diện tích làm việc đa dạng và cung cấp các } \\
\text { hình thức tư vấn, dịch vụ hố trợ nhằm nuôi dưỡng sự phát triển các } \\
\text { doanh nghiệp khởi sự với mục đích tạo công ăn việc làm và phát } \\
\text { triển kinh tế địa phương. }\end{array}$ \\
\hline $\begin{array}{l}\text { Vườn ươm doanh nghiệp công } \\
\text { nghệ (VUDNCN) (technology } \\
\text { business incubator) }\end{array}$ & $\begin{array}{l}\text { Một dạng của VUDN tập trung vào ươm tạo các doanh nghiệp dựa trên } \\
\text { công nghệ (technology based enterprise). }\end{array}$ \\
\hline $\begin{array}{l}\text { Vườn ươm công nghệ (VUCN) } \\
\text { (technology incubator) }\end{array}$ & $\begin{array}{l}\text { Một dạng đặc biệt của VUDN tập trung vào ươm tạo các doanh nghiệp } \\
\text { dựa trên một lĩnh vực công nghệ. }\end{array}$ \\
\hline $\begin{array}{l}\text { Vườn ươm doanh nghiệp công } \\
\text { nghệ cao (VUDNCNC) (high } \\
\text { technology business incubator) }\end{array}$ & $\begin{array}{l}\text { Một dạng đặc biệt của VƯCN tập trung vào ươm tạo các doanh nghiệp } \\
\text { dựa trên lĩnh vực công nghệ cao (hi-tech or new and advanced } \\
\text { technology). }\end{array}$ \\
\hline
\end{tabular}


Có thể thấy rằng các loại vườn ươm sau đều là một dạng đặc biệt của VUDN và chúng đều dựa vào công nghệ. Do vậy, ta có thể gộp cả ba loại thành một và gọi chung là VU'DNCN. Khác với các VỬDN và vườn ươm hỗn hợp nói chung, những VUDNCN chỉ cung cấp những dịch vụ đặc thù và có giá trị giá tăng cao. Trong khi chỉ có một số ít vườn ươm đủ mạnh để cung cấp toàn diện các dịch vụ, thì hầu hết các vườn ươm phải được tài trợ hoặc dựa trên việc liên kết với các nguồn lực tư nhân và nhà nước sẵn có. Các VUDNCN có xu hướng hỗ trợ mạnh hơn các VỦDN nói chung trong việc tìm kiếm nguồn tài trợ, các vấn đề về quyền sở hữu trí tuệ cũng như các vấn đề tiếp thị.

\subsection{Khái niệm doanh nghiệp công nghệ}

Doanh nghiệp công nghệ là doanh nghiệp có hàm lượng cao về nghiên cứu khoa học và phát triển công nghệ tạo ra các sản phẩm, dịch vụ có chất lượng và giá trị gia tăng cao, có khả năng hình thành ngành sản xuất, dịch vụ mới hoặc hiện đại hóa ngành sản xuất, dịch vụ hiện có. Khoản 1 Điều 58 Luật Khoa học và Công nghệ 2013 về doanh nghiệp KH\&CN quy định: "Doanh nghiệp KH\&CN là doanh nghiệp thưc hiện sản xuất, kinh doanh, dịch vu KH\&CN để tạo ra sản phẩm, hàng hóa tù kết quả nghiên cứu khoa học và phát triển công nghệ" [7].

Điều 2 Nghị định số 96/2010/NĐ-CP ngày 20/9/2010 của Chính phủ thì Doanh nghiệp KH\&CN được hiểu là doanh nghiệp mà "hoạt động chính là thực hiện sản xuất, kinh doanh các loại sản phẩm, hàng hoá hình thành từ kết quả nghiên cứu khoa học và phát triển công nghệ do doanh nghiệp được quyền sở hữu, quyền sử dụng hợp pháp; thực hiện các nhiệm vụ KH\&CN. Doanh nghiệp KH\&CN thực hiện sản xuất, kinh doanh và các dịch vụ khác theo quy định của pháp luật" [8].

- Doanh nghiệp công nghệ cao là doanh nghiệp sản xuất sản phẩm công nghệ cao, cung ứng dịch vụ công nghệ cao, có hoạt động nghiên cứu và phát triển công nghệ cao (Khoản 4 Điều 3 Luật Công nghệ cao).

Căn cứ Điểm a và b Điều 75 của Luật Đầu tư và Điều 1 của Quyết định số 19/2015/QĐTTg ngày 15/06/2015 của Thủ tướng Chính phủ, doanh nghiệp công nghệ cao là doanh nghiệp công nghệ, sản xuất sản phẩm công nghệ cao thuộc Danh mục sản phẩm công nghệ cao được khuyến khích phát triển của Nhà nước.

\subsection{Hoạt động ươm tạo và tiền ươm tạo doanh nghiẹp công nghệ}

Trong báo cáo "Mixed-use Incubator Handbook: A Start-up Guide for Incubator Developers" được nghiên cứu năm 2009 của Mark Davies (được tài trợ bởi Information for Development - InforDev và World Bank Group) đã chỉ ra rằng để hiểu về hoạt động của vườn ươm doanh nghiệp công nghệ cần hiểu về chu trình khởi động của một doanh nghiệp theo đó quy trình này gắn liền với 3 giai đoạn của hoạt động ươm tạo bao gồm: tiền ươm tạo, ươm tạo và hậu ươm tạo [9]. Cụ thể như sau:

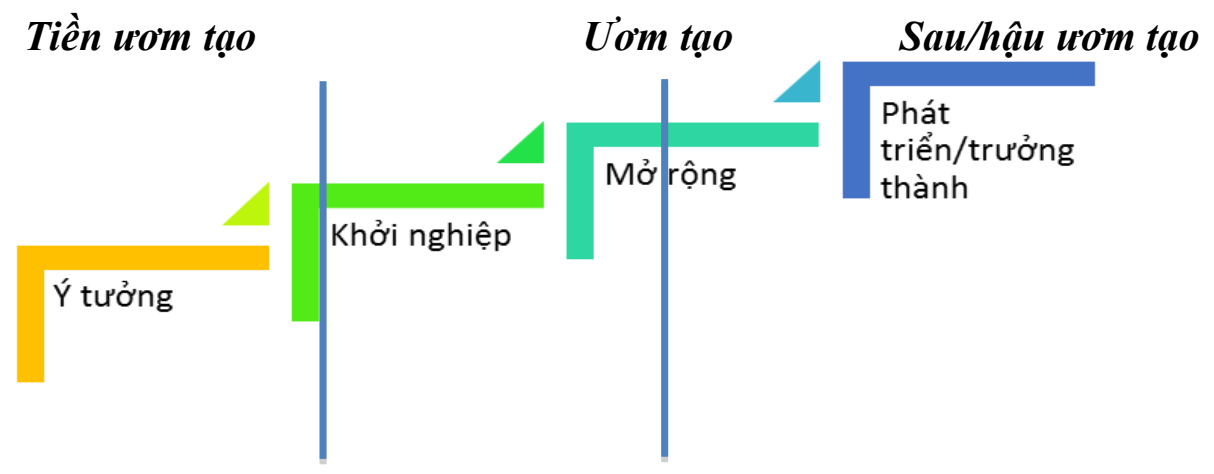

Hình 1. Quá trình tiền ươm tạo, ươm tạo và hậu ươm tạo. 
Tiền ươm tạo

Germinate/

Pre-incubation

Ươm tạo

Incubate/incubation

Hậu ươm tạo

Host/ Post

incubation
Đây là giai đoạn ban đầu của sự can thiệp, khi bạn giúp đỡ 1 cá nhân cùng với ý tưởng của anh ta. Một số cơ sở ươm tạo có thể hỗ trợ hoạt động này nơi mà họ có thể tiếp cận với sự hỗ trợ từ phía cộng đồng hay nguồn vốn cá nhân mạo hiểm. Điều này thường cần thiết trong các lĩnh vực sáng tạo công nghiệp cao và những cơ sở ươm tạo gắn liền với các trường đại học. Đôi khi sự sáng đổi mới đó lại xuất hiện do nhu cầu, hơn là cơ hội và nó mang tính mạo hiểm rất cao.

Đây là giai đoạn một ý tưởng đã phát triển thành một kế hoạch, trong đó một đội ngũ và sự vận hành đã được khởi động. Các cơ sở ươm tạo có thể hỗ trợ sáng lọc kế hoạch, xây dựng nhóm, cung cấp các nguồn lực và đầu tư vào công ty. Đây cũng được xem như là một sự can thiệp khá sớm, trước khi công ty có lợi nhuận. Các công ty thường không đủ khả năng để chi trả cho các dịch vụ, và sự trợ giúp thì chung chung. Giai đoạn này còn được gọi là "Tăng trưởng”, nó tập trung vào các start-up trưởng thành hơn. (Các công ty có thể chi trả cho các dịch vụ và cần sự trợ giúp rõ ràng, có mục tiêu.

Đây là giai đoạn mà một công ty sinh lợi nhuận chỉ tìm kiếm một loại cơ sở vật chất đặc thù. Không sự can thiệp nào từ phía cơ sở ươm tạo bắt buộc ở đây, tuy nhiên chúng tôi bổ sung nó vào đây vì chúng tôi thấy rằng có rất nhiều cơ sở ươm tạo đóng vai trò là những chủ nhà đối với các công ty trong một vài khoảng thời gian, và mối quan hệ này với các công ty trưởng thành có thể trở thành một chiến lược cần thiết để trợ giúp và trợ cấp cho những chương trình khác
Chi phí lớn

Mạo hiểm

Cộng đồng

Các doanh nghiệp start-up Chi phí lớn Trợ cấp 1 phần

Trưởng thành An toàn

Davies (2009), Mixed-use Incubator Handbook: A Start-up Guide for Incubator Developers, Information for Development Program (infoDev) and the World Bank Group.
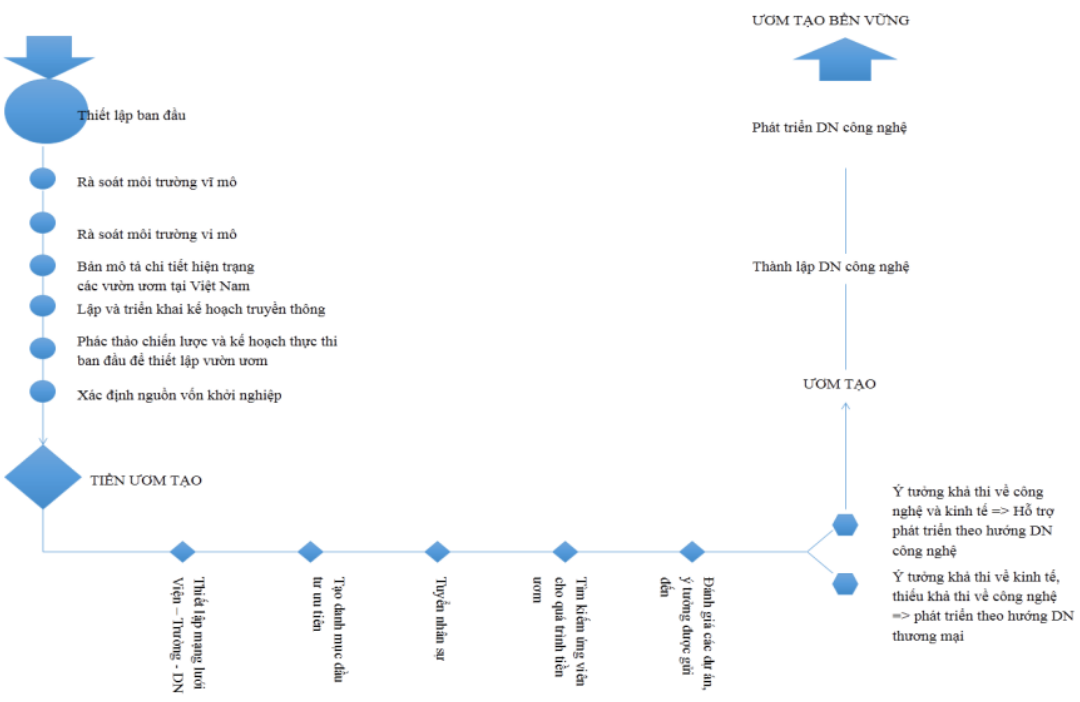

Hình 2. Sơ đồ thể hiện Quy trình tiền ươm tạo và ươm tạo.

Nguồn: Mark Davies (2009), Mixed-use Incubator Handbook: A Start-up Guide for Incubator Developers, Information for Development Program (infoDev) and the World Bank Group. 
Các vườn ươm nhìn chung thường xung quanh các nguồn công nghệ và tri thức, ví dụ viện nghiên cứu,hoặc có mối liên hệ chặt chẽ, để đảm bảo tận dụng được tối đa mạng lưới chuyên gia hay trang thiết bị, nhằm giảm thiểu chi phí ươm tạo ở mức thấp nhất. Vị trí phân bổ như vậy cũng đồng thời giúp giảm thiểu độ trễ thời gian giữa việc phát triển công nghệ và thương mại hóa các kết quả nghiên cứu.

Ngoài ra, các trang thiết bị hỗ trợ có thể là: kho vườn ươm, thiết bị thí nghiệm và hiệu chuẩn, các công cụ về độ chính xác, các trung tâm/phòng thí nghiệm, phát triển vật mẫu, các dịch vụ tạo thuận lợi cho quá trình kinh doanh, máy tính, ngân hàng dữ liệu, thư viện và tài liệu, truyền thông, phòng hội thảo, các trang thiết bị phổ thông khác như điện thoại, máy fax, máy photocopy.... Họ cũng cung cấp các dịch vụ như kiểm tra và hiệu chuẩn, tư vấn, đào tạo, dịch vụ hỗ trợ kỹ thuật, dịch vụ hỗ trợ kinh doanh, dịch vụ cơ sở dữ liệu và tài liệu hướng dẫn, dịch vụ đảm bảo chất lượng và các dịch vụ tiện ích chung.

\subsection{Vai trò của vuờn ươm doanh nghiệp công nghẹ}

\subsubsection{Cơ chế chuyển giao công nghệ}

VU'DNCN có thể được xem như một môi trường chuyển giao kết quả nghiên cứu từ khu vực nghiên cứu hàn lâm hoặc sử dụng tri thức nhận được trong môi trường hàn lâm đến thị trường. Do đó, chuyển giao công nghệ (CGCN) được tiến hành thông qua:

+ Chuyển giao trực tiếp tri thức và/ hoặc công nghệ xuất phát từ khu vực nghiên cứu;

+ Các mối quan hệ thường xuyên với các tổ chức nghiên cứu đặc biệt - quan hệ được thiết lập giữa các tổ chức cho phép sự truyền bá thông tin, tri thức và di chuyển cán bộ;

+ Các quan hệ không thường xuyên với một hoặc một loạt các tổ chức.

Như vậy, việc tạo ra cầu nối giữa hai môi trường nghiên cứu và sản xuất cho phép thúc đẩy hơn nữa sự truyền bá thông tin hoặc tri thức công nghệ, đồng thời nó cũng cho phép sự điều chỉnh nhất định: các doanh nghiệp có thể xác định tốt hơn nhu cầu của họ và do đó đầu vào của các doanh nghiệp thoả đáng hơn; bên cạnh đó các tổ chức nghiên cứu cũng thu được cách nhìn tổng quát hơn về những đòi hỏi của thị trường, giúp các tổ chức này xác định các hướng nghiên cứu thích hợp hơn đối với nhu cầu của khu vực công nghiệp.

\subsubsection{Khuyến khich hoạt động đổi mới}

Từ các khái niệm nêu trên có thể thấy, VUDNCN là một loại hình đặc thù và đang nổi lên của ươm tạo doanh nghiệp vì trên thực tế hoạt động ứng dụng đổi mới công nghệ hầu hết đều do các DNCN tiến hành.

Kể từ những năm 1980, VỦDNCN đã trở thành một trong những nội dung trọng tâm trong chính sách công nghệ và đổi mới ở Bắc Mỹ, châu Âu và gần đây nhất là Nhật Bản. VU'DNCN quan trọng là do tầm quan trọng ngày càng gia tăng của các doanh nghiệp nhỏ và vừa $(\mathrm{DNNVV})$. DNNVV dựa vào công nghệ sẽ là những cơ sở quan trọng để tạo ra việc làm, tạo điều kiện thuận lợi cho sự thay đổi về cơ cấu và khuyến khích tăng trưởng kinh tế.

Tuy nhiên, bản thân khái niệm và cách phân loại VU'DNCN cũng khác xa nhau giữa các quốc gia. Nếu căn cứ vào mối quan hệ giữa VU'DNCN và cơ quan chủ trì/vận hành vườn ươm thì có thể thấy hiện nay không có một mô hình thống nhất về VUDNCN. Trong hầu hết các trường hợp, VUDNCN là đơn vị chi nhánh của một trường đại học, công viên khoa học hoặc trung tâm đổi mới. Trong một số trường hợp khác, VUDNCN là một bộ phận chức năng của một công viên khoa học (Anh), hoặc Trung tâm đồi mới/công nghệ (Đức), hoặc có thể là một đơn vị riêng biệt hoạt động ở một khu cơ sở hạ tầng tri thức của trường đại học hoặc công viên KH\&CN (Mỹ, Nhật Bản và Pháp). VUDNCN có thể do một tổ chức tài trợ (chủ sở hữu) quản lý, điều hành nhưng có một số trường hợp do nhiều bên góp vốn. VU'DNCN còn do các cơ quan nhà nước thành lập với sự phối hợp chặt chẽ với các cơ sở KH\&CN có định 
hướng trọng tâm vào thương mại hoá các công nghệ gần gũi với thị trường.

\subsubsection{Nơi nuôi duõng doanh nghiẹp công nghệ}

VUDNCN là động lực cho sự phát triển của các doanh nghiệp xét theo khía cạnh các VUDNCN có các tiêu chuẩn về nhà xưởng cho thuê, đặc biệt thuận lợi đối với các doanh nghiệp khởi sự trong lĩnh vực công nghệ cao. VU'DNCN được xem xét như một tổ chức được thành lập để hỗ trợ cho các doanh nghiệp khởi sự trong lĩnh vực công nghệ trong việc phát triển các doanh nghiệp mới. Thông qua quá trình hỗ trợ các doanh nghiệp công nghệ và doanh nghiệp khởi sự, các VU'DNCN tìm kiếm sự kết hợp năng lực kinh doanh, công nghệ, vốn, tri thức như là lực đẩy đối với sự phát triển của các doanh nghiệp công nghệ cũng như các doanh nghiệp khởi sự, bên cạnh đó các VUDNCN còn đạt được lợi ích của mình đó là thương mại hoá công nghệ đến với thị trường/khách hàng.

\subsubsection{Công cu chính sách}

Lý do cơ bản khiến nhà nước cần phải hỗ trợ cho các VU'DNCN nói chung là tình trạng thất bại trên thương trường của nhiều DNNVV đã dẫn đến hiện tượng "nản chí" trong việc thành lập doanh nghiệp mới của nhiều doanh nhân. Các chủ DNNVV phải đối mặt với nhiều trở ngại khi bắt đầu khởi sự doanh nghiệp, mà những trở ngại chính xuất phát từ yêu cầu phải đầu tư cho các tài sản cố định và chi phí thâm nhập thị trường cao trong khi doanh nghiệp lại thiếu cơ hội tiếp cận tới các nguồn tài trợ từ các định chế tài chính một cách bình đẳng trong cùng một môi trường với các doanh nghiệp lớn, thiếu thông tin thị trường, thiếu năng lực xử lý các vấn để đòi hỏi kỹ thuật cao, điều quan trọng hơn là trình độ quản lý doanh nghiệp còn yếu kém.

Trong nhiều trường hợp, những mục tiêu của VUDNCN phản ánh nội dung chính sách của chính phủ, trong đó những tổ chức này hoạt động ở cấp địa phương, cấp vùng và quốc gia. Hiện nay trên thế giới có rất nhiều mô hình vườn ươm doanh nghiệp công nghệ như: mô hình đơn sở hữu, đa sở hữu; phát triển vườn ươm thông qua hỗ trợ của mạng lưới các doanh nghiệp; hợp tác quốc tế; mô hình vườn ươm tại trường đại học,... Sự phát triển và thành công của mô hình vườn ươm doanh nghiệp công nghệ tại các nước trên thế giới như Trung Quốc, Thụy Điển, Mỹ,... và ngay tại quốc gia trong khu vực như Trung Quốc, Hàn Quốc, Đài Loan, Singapore,... đã chứng minh vai trò tích cực của mô hình vườn ươm. Vườn ươm doanh nghiệp công nghệ có ý nghĩa lớn:

Thư nhất, vườn ươm doanh nghiệp tạo điều kiện, là chất xúc tác giúp các doanh nghiệp khởi sự thành công, phát triển tinh thần kinh doanh.

Thư hai, đây được coi là công cụ thúc đẩy sáng tạo, đổi mới, chuyển giao công nghệ và thương mại hoá thành công các ý tưởng công nghệ nhờ gắn kết chắt chẽ hơn mối quan hệ trường đại học - viện nghiên cứu - doanh nghiệp.

Thú $b a$, vườn ươm có tác động tích cực tới mối quan hệ Doanh nghiệp- Chính phủ, là nơi kiểm nghiệm sự phù hợp, hiệu quả của các chính sách của chính phủ.

Thư $t u$, cung cấp quỹ hạt giống (seed funding) cho các doanh nghiệp khởi nghiệp hoặc giúp đỡ các doanh nghiệp tìm kiếm, gia tăng nguồn vốn hạt giống.

Thư năm, đóng vai trò kết nối các doanh nghiệp khởi nghiệp với mạng lưới nguồn lực để gia tăng cơ hội sống sót và tăng trưởng.

\section{Kết luận}

Trong xã hội hiện đại, trình độ khoa học là yếu tố then chốt để phát triển kinh tế. Các quốc gia trên thế giới, trong đó có cả Việt Nam đều nỗ lực tăng cường năng lực phát triển thông qua hoạt động KH\&CN. Sự gắn kết giữa nghiên cứu và sản xuất đòi hỏi phải chú trọng đầu tư vào khâu "ươm tạo" để giúp các doanh nghiệp công nghệ mới lớn mạnh, đạt tới quy mô thương mại. Mô hình vườn ươm doanh nghiệp được hình thành và phát triển tại Việt Nam như là một giải pháp "cứu cánh" dành cho các doanh nghiệp. 
Tại đây, các nhà đầu tư sẵn sàng chấp nhận các rủi ro, đối mặt với các nguy cơ thất bại lớn để đầu tư vào các doanh nghiệp trẻ nhưng có ý tưởng và năng lực sáng tạo tốt. Từ đó, nuôi dưỡng và hình thành các doanh nghiệp công nghệ. Các doanh nghiệp công nghệ sẽ là yếu tố tạo nên hiệu quả đột phá cho cả nền $\mathrm{KH} \& \mathrm{CN}$ và nền kinh tế - xã hội của Việt Nam trong bối cảnh hội nhập quốc tế.

\section{Tài liệu tham khảo}

[1] UNIDO (1999), Component 3, Technology Business Incubators and Technology Parks, Indepth evaluation of selected UNIDO activities on development and transfer of technology.p.3

[2] United Kingdom Business Incubation (UKBI) (2003), Benchmarking framework for business incubation: final report, January 2003, UK Business Incubation, p.2

[3] SPICA Directory Online - http://www.spicadirectory.net/definitions/
[4] Center for Technology Transfer (2014), Business Incubation in the USA, p.145-146

[5] Quốc hội (2006), Luật Chuyển giao công nghệ số 80/2006/QH11, Hà Nội.

[6] Thủ tướng Chính phủ (2015), Quyết định số 1139/QĐ-TTg về việc Thí điểm một số cơ chế, chính sách đặc thù phát triển Vườn ươm doanh nghiệp công nghệ Việt Nam - Hàn Quốc tại thành phố Cần Thơ.

[7] Quốc hội (2013), Luật Khoa học và Công nghệ số 29/2013/QH13, Hà Nội.

[8] Thủ tướng Chính phủ (2010), Nghị định số 96/2010/NĐ-CP ngày 20/9/2010 của Chính phủ sửa đổi bổ sung một số điều của Nghị định số 115/2005/NĐ-CP ngày 05/9/2005 quy định cơ chế tự chịu trách nhiệm của tổ chức khoa học và công nghệ và Nghị định số $80 / 2007 / \mathrm{NĐ}-\mathrm{CP}$ ngày 19/5/2007 của Chính phủ về doanh nghiệp $\mathrm{KH} \& \mathrm{CN}$.

[9] Mark Davies (2009), Mixed-use Incubator Handbook: A Start-up Guide for Incubator Developers, Information for Development Program (infoDev) and the World Bank Group.

\title{
Some Theoretical Issues in the Study of Promoting the Formation of Technology Enterprises through Technology Business Incubator
}

\author{
Pham Dai Duong, Dao Thanh Truong \\ Ministry of Science and Technology, 113 Tran Duy Hung, Cau Giay, Hanoi, Vietnam \\ VNU University of Social Sciences and Humanities, 336 Nguyen Trai, Hanoi, Vietnam
}

\begin{abstract}
The concept of "business incubator" has appeared in Vietnam for nearly 10 years, however, for the majority of Vietnamese businesses and people, this term is still quite new. For that reason, there are not many studies on technology business incubation and they have just been able to identify the difficulties in some incubators and offer specific incubator development schemes. The technology business incubator in Vietnam has not been recognized and evaluated comprehensively. Technology business incubator (TBI) is one type of business incubator that focuses on the incubation of technology-based enterprises. TBI can be considered as an environment for transferring research results from academic areas to markets, encouraging innovation, nurturing and forming technology enterprises. It also plays as a policy tool to support the development and establishment of SMEs. In addition, the authors will discuss the role of TBI as well as the three stages of incubation including: pre-incubation, incubation and post-incubation with specific procedures and characteristics.
\end{abstract}

Keywords: Incubator, technology business, technology business incubator, TBI, business incubator. 